\title{
La atenuación pragmática como estrategia de acercamiento en el Español de la Salud: propuesta didáctica
}

Marta GANCEDo RUIZ

Universidad de Valencia / CIESE-Fundación Comillas

Resumen: El objetivo de este trabajo es aportar una nueva manera de desarrollar la competencia pragmática de los alumnos de Español de la Salud. Para ello, se propone introducir en el aula el trabajo con una estrategia pragmática concreta para facilitar las relaciones médico-paciente, la atenuación, a través de secuencias didácticas contextualizadas en tres situaciones comunicativas concretas del ámbito hospitalario: la exploración física, la transmisión de malas noticias y la reprobación de malas conductas con consejo médico.

Palabras clave: Español con Fines Específicos, atenuación, competencia pragmática, relación médico-paciente.

Abstract: The aim of this article is to provide a new way to develop the pragmatic competence in Spanish for Medical Purposes. In order to do this, it is suggested to introduce in the classroom the work with a specific pragmatic strategy, mitigation, in order to make easier the doctor-patient communication by using didactic sequences contextualised in three medical situations of the medical context: medical examination, giving bad news and rejection of misconduct.

Keywords: Spanish for Specific Purposes, mitigation, pragmatic competence, doctorpatient relationship 


\section{Introducción}

En los últimos años, la demanda de cursos de Español Profesional de la Salud ha aumentado vertiginosamente (Andrés González y Lanzarote Rojo, 2009), pues en algunos países, como EEUU, los pacientes tienen derecho a ser atendidos en su lengua materna (Jacobson, 2001).

Los profesionales del ámbito sanitario (médicos, enfermeros, dentistas, etc.) presentan un perfil especial como estudiantes del Español con Fines Profesionales, pues no solo pretenden adquirir una competencia en español de la lengua de especialidad, sino que buscan especialmente desarrollar una competencia pragmática que les ayude a lograr una comunicación cercana y eficiente con sus pacientes. Por ello, y teniendo en cuenta las variedades socioculturales que atañen a las cuestiones de imagen y roles sociales de la delicada relación médico-paciente, es fundamental introducir en clase de Español de la Salud aspectos relativos al cuidado de la imagen del paciente. De este modo, podrán evitarse así no solo malentendidos, sino situaciones en las que este pueda sentirse cohibido o incluso ofendido.

Una de las estrategias comunicativas que ayudan al cuidado de la imagen es la atenuación pragmática, cuya introducción en el aula de Español de la Salud proponemos en este artículo. Así, nuestro objetivo principal presenta una doble naturaleza: por una parte, defenderemos la pertinencia de introducir la atenuación pragmática en el aula del Español de la Salud; por la otra, y de índole más práctica, propondremos secuencias de actividades que permitan al profesor trabajar esta estrategia en el aula.

Para ello, comenzaremos realizando un breve acercamiento teórico al concepto de competencia pragmática y a las necesidades concretas de un alumno de Español de la Salud. Seguidamente, realizaremos una breve reflexión teórica sobre los conceptos de imagen sociocultural, rol y atenuación, y, por último, después de explicar la metodología adoptada para su diseño, presentaremos una serie de secuencias didácticas para que el profesor pueda trabajar con sus alumnos la atenuación como estrategia de acercamiento al paciente.

\section{La competencia pragmática en el aula del Español de la Salud}

El área de interés de este artículo se enmarca en una línea muy concreta de la didáctica de español: el Español con Fines Profesionales (EFP). Las necesidades de un alumno de español general y las de un alumno de EFP de cualquier área laboral son muy diversas, por lo que los objetivos, contenidos, métodos de trabajo y evaluación de un curso para este alumnado deben ser diferentes a los de un curso de español general.

En este trabajo, adoptamos la definición de Aguirre Beltrán del EFP como

el enfoque del proceso de enseñanza-aprendizaje, basado en la comunicación y orientado a la consecución de una determinada competencia comunicativa, que tiene como propósito mejorar las capacidades de comprensión, expresión, interacción o mediación que se requieren para desenvolverse efectiva y eficazmente en un determinado campo de actividad.

(2012: 13)

En este caso, el campo de actividad al que dirigimos nuestra propuesta es el ámbito sanitario, y concretamente, a los profesionales de la Medicina. 
En esta área, los intercambios comunicativos pueden desarrollarse entre interlocutores experto-experto (es decir, médico-médico) o experto-inexperto (médico-paciente, médico-familiares de paciente, médico en labores de divulgación-público general). Si bien en el primer caso el dominio de la lengua de especialidad (el lenguaje médicocientífico) es fundamental, nuestro trabajo se enfoca en los intercambios del segundo tipo, en concreto, a los realizados entre médico (experto) y paciente (inexperto). Por lo tanto, no nos centramos tanto en el desarrollo del conocimiento de la lengua de especialidad en nuestros alumnos, sino que nuestro objetivo fundamental es el desarrollo de la competencia pragmática de estos, entendida como

capacidad de un hablante para realizar un uso comunicativo de la lengua en el que se tengan en cuenta no solo las relaciones que se establecen entre los signos lingüísticos y sus referentes, sino también las relaciones pragmáticas; es decir, aquellas que se originan entre el sistema de una lengua y los interlocutores y el contexto discursivo.

Aguirre Beltrán (2012: 22)

En la totalidad de los análisis de necesidades realizados a los alumnos del curso Español para la Salud, desarrollado en la Fundación Comillas, estos manifestaban que su principal inquietud con respecto al español no es un dominio correcto de la lengua, sino el desarrollo de una competencia comunicativa que, aunque no esté exenta de errores, les permita conectar con el paciente y así poder desarrollar con eficacia la faceta social de su trabajo.

La propuesta didáctica que aquí presentamos trabaja con una estrategia pragmática concreta, la atenuación, que contribuye a una relación menos jerarquizada $y$, por lo tanto, más cercana entre médico y paciente en situaciones comunicativas determinadas dentro del contexto sanitario.

\section{La atenuación pragmática como estrategia de acercamiento al paciente}

Como ha sido mencionado en el apartado anterior, para los alumnos del Español de la Salud una de las prioridades es lograr establecer una comunicación eficiente, pero a la vez cercana con sus pacientes y los familiares de estos.

Esto no siempre es tarea fácil, pues más allá de las posibles barreras lingüísticas, se encuentra una jerarquización social que ha colocado tradicionalmente a los médicos en una posición de superioridad que muchas veces genera que el paciente sienta una sensación de distancia y cierta vulnerabilidad frente al doctor. Esta concepción de distancia social es posible explicarla gracias al concepto sociopragmático de imagen sociocultural. El origen de este término se encuentra en la antropología, concretamente en la obra de Goffman (1959), quien definió face como la representación metafórica del compromiso del individuo con su presentación en sociedad. Así, en toda interacción, el individuo, además de transmitir su intención comunicativa, está proyectando su imagen social, es decir, la concepción social de sí mismo que desea transmitir a sus interlocutores. Siguiendo las ideas de la pragmática sociocultural, la imagen está fuertemente determinada socioculturalmente (Bravo, 1998,1999, 2010, entre otros), por lo que varía de unas comunidades de habla a otras. Por esta razón, es fundamental incluir en todos los procesos de enseñanza-aprendizaje de una segunda lengua aspectos relacionados con la 
imagen social de cada cultura, pues su conocimiento y manejo afecta al desarrollo de la competencia pragmática del alumno en la lengua meta.

Igualmente, no es solo el contexto sociocultural el que define la imagen, sino que esta está a su vez fuertemente determinada por el rol, es decir, por el papel conversacional que desempeña cada interlocutor: en palabras de Hernández Flores, «en una situación de habla el deseo de imagen de una persona depende del rol que representa en cada situación de habla concreta» (2003: 124). De este modo, un mismo hablante tendrá unas necesidades y deseos de imagen diferentes, $y$, por tanto, una conducta comunicativa diversa, según se desenvuelva en una conversación como padre, como hijo o como médico.

Además, las imágenes de los hablantes son dinámicas, varían en el transcurso de los intercambios, y pueden verse mantenidas, realzadas, amenazadas o incluso perjudicadas. Así, para gestionar su proyección, los hablantes cuentan con unos recursos comunicativos, las actividades de imagen. Si estas estrategias están encaminadas a cuidar las imágenes de los hablantes se consideran actividades de cortesía, si se destinan solo a beneficiar la imagen del hablante son conocidas como actividades de autoimagen, y si por el contrario provocan un ataque a la imagen de alguno de los interlocutores, son actividades de descortesía (Hernández Flores, 2013).

En la relación que atañe a este artículo, la concerniente a médico-paciente, tradicionalmente se han considerado dos roles en situación socio-funcional jerárquica, en la que el médico se situaría en la posición superior. De este modo, para conseguir un acercamiento entre las imágenes de ambos interlocutores y que el paciente pueda percibir menor distancia social con el doctor, es deseable que el interlocutor en rol de médico utilice estrategias pragmáticas de cortesía que faciliten el equilibrio entre ambas imágenes.

Una de las estrategias comunicativas que facilitan el cuidado de la imagen del otro es la atenuación. Esta estrategia pragmática puede definirse como

una estrategia pragmática (comunicativa) originada por necesidades de imagen y dirigida a mitigar y minimizar la intensidad de lo que se expresa reduciendo la fuerza ilocutiva del acto de habla, y en ocasiones, a través de mecanismos de lenguaje vago por los que se difumina o minimiza el contenido proposicional.

Albelda Marco (2016: 32).

Por lo tanto, puede decirse que, a través de la reducción de la fuerza del mensaje, el hablante, en este caso el médico, logra un acercamiento al receptor (en el rol de paciente).

Así, si enseñamos a nuestros alumnos, profesionales del ámbito de la salud, qué circunstancias pueden hacer que los pacientes sientan amenazadas sus imágenes o en fuerte desequilibrio con respecto a la del médico, así como qué tácticas lingüísticas concretas en español funcionan como atenuantes de este desequilibrio o potencial amenaza, incrementaremos de forma notable su competencia pragmática. Esto, a su vez, facilitará el mejor desarrollo de la faceta social de su praxis profesional, pues podrán establecer una conexión más personal con sus pacientes.

De esta manera, con las secuencias que proponemos en el siguiente apartado, se trata de que el alumno sea consciente de los efectos comunicativos y sociales de ciertos usos lingüísticos con respecto no solo a una cultura sino también a un rol determinado. 


\section{Propuesta didáctica}

\subsection{Metodología}

Para diseñar las secuencias didácticas que presentamos en este artículo, hemos seguido la siguiente metodología:

En primer lugar, hemos seleccionado tres situaciones comunicativas características del ámbito sanitario con riesgo potencial para la imagen del paciente: la exploración física, la transmisión de malas noticias y la reprobación de malas conductas con consejo médico.

Después, para determinar qué tácticas lingüísticas trabajar, hemos acudido al repertorio realizado dentro del proyecto de investigación (surgido en el seno del grupo de investigación Val.Es.Co) Es.Var.Atenuación (Albelda, Briz et alii 2014) y hemos extraído aquellos recursos lingüísticos que, a partir de nuestras intuiciones como hablantes, hemos considerado más pertinentes para las situaciones comunicativas previamente seleccionadas.

En cuanto al enfoque didáctico de la atenuación como estrategia comunicativa, nos hemos decantado por el tratamiento explícito de la misma, pues como sostiene Bartol, ello «provocará una toma de conciencia por parte de los alumnos y una valoración más relevante de este recurso» (2003: 52).

Del mismo modo, seguimos a la autora al defender una enseñanza gradual y secuenciada de la atenuación (razón por la cual no presentamos una unidad didáctica sino unas secuencias didácticas que se pueden integrar en diferentes momentos del curso cuando el profesor lo estime oportuno), un «contacto práctico, sin una caracterización demasiado teórica o un lenguaje plenamente metalingüístico», $\mathrm{y}$, especialmente, el importante papel del profesor como motivador de la reflexión sobre los efectos comunicativos de la atenuación (Bartol, 2003: 52).

\subsection{Desarrollo de las actividades}

A continuación, presentamos tres secuencias didácticas de un nivel aproximado de B2C1 para un curso de Español de la Salud que, utilizando como métodos de trabajo principales la concienciación formal y el role-play, se integrarían en unidades didácticas más amplias. Los objetivos generales de estas secuencias didácticas son los siguientes:

1. Fomentar la reflexión de los estudiantes sobre las creencias hispanas de la relación médico-paciente.

2. Reconocer situaciones comunicativas del ámbito sanitario con riesgo para la imagen del paciente.

3. Manejar eficazmente un amplio número de recursos lingüísticos para expresar atenuación pragmática en diferentes actos comunicativos propios de la labor profesional sanitaria.

De este modo, en cada secuencia trabajaremos el empleo de unas tácticas lingüísticas concretas para una función comunicativa determinada:

1. Secuencia 1 «La exploración física»:

- Objetivos: desarrollar recursos para atenuar la formulación de instrucciones al paciente durante la exploración física y mostrar cercanía con él 
- Recursos lingüísticos: diferentes grados de indirección en las peticiones, fórmulas apelativas y dativos éticos, cuantificadores minimizadores y diminutivos

2. Secuencia 2 «La transmisión de malas noticias»:

- Objetivos: desarrollar recursos para facilitar la comunicación de malas noticias al paciente a través de la atenuación pragmática

- Recursos lingüísticos: eufemismos, lítotes y difusores del significado

3. Secuencia 3 «La reprobación de malas conductas con consejo médico»:

- Objetivos: desarrollar recursos para atenuar el impacto negativo de las reprobaciones y consejos en la imagen del paciente

- Recursos lingüísticos: impersonalizaciones, fingimiento de duda, inclusión de la primera persona

\subsubsection{Secuencia 1: La exploración física}

Para introducir la secuencia, el profesor guía la realización de una reflexión grupal sobre el posible sentimiento de temor e inseguridad de un paciente cuando llega a urgencias o al centro de salud y es necesario realizarle una exploración física. Se tratará de llegar a la conclusión de que estos sentimientos, unidos a la consideración social que se tiene de los médicos, pueden provocar que muchas veces el paciente se sienta especialmente vulnerable, por lo que el personal sanitario debe cuidar la forma de dirigirse a él. A continuación, se presentarán las siguientes actividades, que terminarán con la reflexión lingüística que se presenta en el cuadro final:

1.Observa las indicaciones que el médico da a don Pedro, un anciano que ha acudido a urgencias por malestar general y fuerte tos con expectoración, durante la exploración física:

Ahora, si no le importa, voy a explorarle. ¿Podría desnudarse de cintura para arriba? / Túmbese un poco en la camilla, por favor / Bájeme las piernas / Inspire aire fuerte, don Pedro, y suéltelo despacito / Vuelva un poco a coger aire y aguántemelo, don Pedro / Eso es, ¡muy bien! / ¿Puede ahora ponerse un poco de costado? / Póngame el brazo debajo de la cabeza y de nuevo inspire fuerte.

2.Clasifica las órdenes o instrucciones que da el médico:

\begin{tabular}{|l|l|}
\hline ÓRDENES DIRECTAS & ÓRDENES INDIRECTAS \\
\hline Túmbese un poco en la camilla & $\begin{array}{l}\text { ¿Podría desnudarse de cintura para } \\
\text { arriba? }\end{array}$ \\
\hline
\end{tabular}

3.Observad ahora en parejas las órdenes formuladas directamente, ¿qué recursos lingüísticos observáis para suavizar la fuerza del imperativo?

Para no resultar demasiado directos, podemos rebajar la fuerza de nuestras instrucciones añadiendo un pronombre indirecto de primera persona al imperativo. Este pronombre transmite implicación y cercanía con el interlocutor (ábreme la boca, levántame el brazo). Otras técnicas lingüísticas que podemos utilizar para minimizar el coste de la orden son los minimizadores, 
como los diminutivos (suba el brazo un poquito, espere aquí un minutín, etc.) o la expresión un poco.

A continuación, se invita a los alumnos a que comenten otras estrategias lingüísticas que puedan hacer sentir al paciente la cercanía del médico. Si no lo dijeran los propios estudiantes, el profesor puede mencionar que para que el paciente sienta mayor implicación por parte del médico, es positivo repetir su nombre y, si es un señor o señora mayor, se sentirá bien si se antepone don / doña a su nombre de pila y se le trata de usted (a no ser que indique lo contrario); si es una persona joven, el nombre de pila y el trato de tú puede favorecer una relación de iguales. Por último, se cierra la secuencia con las siguientes actividades de práctica:

4.Practica estas tácticas lingüísticas en las siguientes órdenes recurrentes en una exploración física:

Póngase recto.

Póngase boca arriba.

Estire el brazo.

Doble la rodilla.
Súbase las mangas

Desabróchese el pantalón

Mire hacia arriba

Vístase

5.En parejas, simulad una exploración médica. Cuando terminéis, no olvidéis completar el informe Anamnesis y exploración. Elegid alguno de los siguientes casos:

María, 61 años, ha sufrido un desvanecimiento mientras cocinaba.

Pedro, 19 años, ha sufrido una fuerte caída mientras practicaba ciclismo.

\subsubsection{Secuencia 2: La transmisión de malas noticias}

La secuencia comienza con una introducción general del profesor, quien explica los consejos del doctor Rodríguez Salvador para la transmisión de malas noticias:

1.Preparación del entorno

2.Percepción del paciente

3.Averiguación sobre si el paciente quiere tener conocimiento

4. Introducción con eufemismos y mitigaciones

5.Observación de la reacción del paciente

6. Explicación de la enfermedad

7.Demostración de empatía y respeto

8. Indagación del efecto de la noticia

9. Demostración de apoyo

10. Disminución de la angustia.

Rodríguez Salvador (2010)

Inmediatamente centrará la atención en el paso cuatro, destinado a que el paciente o su familia se vayan preparando para recibir la mala noticia, antes de mencionarla 
explícitamente, ya que, según este experto, antes de explicar la enfermedad conviene acercarse a ella gradualmente. Para trabajar este punto, se plantean las siguientes actividades:

1.Observa las siguientes expresiones en las que el médico introduce un diagnóstico negativo a un paciente.

Hemos detectado algo que nos preocupa.

Hay algunos aspectos que nos preocupan en sus análisis.

Los resultados nos avisan de que algunas cosas no van del todo bien.

- ¿Qué función crees que tienen las expresiones marcadas?

2. Otra manera de atenuar el impacto de la mala noticia es introducirla a través de un eufemismo. A continuación, sustituye los términos médicos exactos por el eufemismo correspondiente:

* Tiene el sistema inmunitario demasiado debilitado para ser intervenido

* Su padre necesita ventilación mecánica

* Ha sufrido un infarto

* Existen altas posibilidades de esclerosis múltiple

$>$ conjunto de células anormales

$>$ cierta ayuda para respirar

$>$ problema cardíaco

$>$ algunas alteraciones en el sistema nervioso

$>\quad$ un problema con sus defensas

* Se ha detectado un tumor

3.En parejas, analizad las siguientes expresiones, ¿qué significan? ¿Qué táctica utiliza el médico para que el paciente sufra menos impacto?

Los resultados no son muy esperanzadores

No tiene buena pinta

El tratamiento no es muy ligero

Las lítotes, es decir, la negación de lo contrario, es una manera de adelantar una mala noticia suavizando su impacto inicial.

4.Transforma los siguientes enunciados suavizando su fuerza a través de lítotes:

Los resultados de las pruebas son negativos.

La masa detectada es maligna.

La recuperación total de la movilidad es prácticamente imposible.

Una vez finalizado el trabajo con todas las etapas previamente mencionadas en la transmisión de malas noticias, se plantea la siguiente actividad final:

5.En parejas, simulad cómo introduciríais la transmisión de las siguientes malas noticias:

Enfermedad de Wilson

Tumor maligno en una mama 
Pocas posibilidades de recuperación total del habla después de sufrir un ictus Parkinson

\subsubsection{Secuencia 3: Reprobación de malas conductas con consejo médico}

Para introducir la secuencia, el profesor presenta a los alumnos el siguiente caso:

Carlos es tu paciente desde hace años. Por una serie de circunstancias comenzó a desarrollar sobrepeso y diabetes tipo 2. Pese a que cuando se le comunicó el diagnóstico hace seis meses se le dieron algunas pautas, Carlos continúa sin practicar deporte, fumando y sin llevar una alimentación sana ni beber suficiente agua. En las últimas semanas ha sufrido hiperglucemia severa así que es necesario que cambie algunos hábitos para mantener su glucemia controlada. Carlos es una persona sensible y con tendencia al sentimiento de culpabilidad.

El profesor sugiere la siguiente intervención con Carlos:

Parece que no estamos siendo muy estrictos con la dieta, ¿no? Los resultados dicen que tienes 142 de azúcar en sangre asi que vamos a empezar a tomarnos muy en serio la dieta. Además, Carlos, hay que hacer ejercicio, al menos un paseo de 30 minutos al día, generalmente se tiende a una vida sedentaria pero en casos como el tuyo debemos cuidarnos más.

Además, a todos nos gusta comer dulce, pero con diabetes debemos saber que es una conducta de riesgo, asi que vamos a quitar toda la bollería industrial y a cambiarla por unas tres piezas de fruta al día, ¿cómo lo ves?

1.Identifica en la intervención del médico consejos o prescripciones y reprobaciones a Carlos por sus malos hábitos:

\begin{tabular}{|l|l|}
\hline CONSEJOS O PRESCRIPCIONES & REPROBACIONES \\
\hline & \\
\hline
\end{tabular}

2.En parejas, reflexionad: teniendo en consideración el carácter de Carlos, ¿cuáles son los más agresivos con el paciente? ¿Y los más cercanos? ¿Por qué?

3.Completad el cuadro con ejemplos de las estrategias lingüísticas que pueden ayudarnos a una comunicación más cercana con nuestro paciente:

Para suavizar la fuerza de nuestras prescripciones, podemos:

- buscar la cercanía con nuestro paciente apelándole a través de preguntas de comprobación de acuerdo.

Ejemplo del texto:

Otros ejemplos:

- incluirnos en el cumplimiento de la orden a través del uso de la primera persona del plural.

Ejemplo del texto:

Otros ejemplos: 
Para que nuestras reprobaciones resulten menos agresivas, podemos:

- incluirnos en el no cumplimiento de la prescripción previa con el uso de la primera persona del plural.

Ejemplo del texto:

Otros ejemplos:

- utilizar verbos que expresen opinión o realidad en forma de probabilidad

Ejemplos del texto:

Otros ejemplos

- generalizar el mal hábito a través de expresiones como a todos, es frecuente, generalmente, se tiende a...

Ejemplos del texto:

Otros ejemplos:

4.En parejas, pensad qué hábitos han podido hacer empeorar la salud de los pacientes con las siguientes enfermedades y cuál sería el consejo médico. Vamos a simular un diálogo en una consulta médica en el que médico y paciente conversen sobre cada una de las enfermedades. El médico puede utilizar las estrategias de acercamiento que hemos trabajado:

$\begin{array}{lll}\text { Artritis } & \text { Infección de orina recurrente } & \text { Fibromialgia }\end{array}$

\section{Conclusiones}

A la luz de las reflexiones teóricas vertidas y del diseño de las actividades planteadas, hemos llegado a las siguientes conclusiones:

En primer lugar, estimamos que el trabajo con estrategias pragmáticas, y concretamente con la atenuación, no es solo posible, sino necesaria para optimizar la praxis profesional de los estudiantes del Español de la Salud. Así, mediante el refuerzo de la competencia pragmática del alumno, podrá analizar mejor las situaciones comunicativas de su ámbito profesional y reflexionar sobre los efectos en la imagen de los pacientes que pueden tener sus palabras. De esta manera, podrá verse reforzado el desempeño de la faceta social de su trabajo en español, ya que podrá establecer conversaciones con sus pacientes en las que estos vean sus imágenes equilibradas.

De este modo, a través de la propuesta didáctica presentada, hemos pretendido facilitar la manera de introducir en el aula el trabajo con una estrategia pragmática concreta, la atenuación, en situaciones comunicativas típicas de la relación médico-paciente.

No obstante, somos conscientes de las propias limitaciones de estas secuencias pues sería deseable trabajar con un corpus del español oral sanitario (preferentemente hospitalario) para poder crear secuencias basadas en muestras de lengua real.

Además, creemos que se abren posibles futuras líneas de investigación, ya que estimamos que es posible extrapolar este tipo de actividades encaminadas al desarrollo de estrategias pragmáticas a otros ámbitos como el Español de la Diplomacia, Jurídico, de los Negocios, etc. 


\section{Bibliografía}

Andrés GonzÁlez, P. y LANZAROte Rojo, J. (2009). «Curarse en salud: enfoques para la enseñanza del español médico». En A. Vera Luján e I. Martínez Martínez (eds.), El español en contextos específicos: enseñanza e investigación. XX Congreso Internacional de la Asociación para la Enseñanza del Español como Lengua Extranjera (ASELE) (pp. 1009-1054). Comillas: Fundación Comillas.

Aguirre Beltrán, B. (2012). Aprendizaje y enseñanza de español con fines específicos. Comunicación en ámbitos académicos y profesionales. Madrid: SGEL

Albelda Marco, M. (2016). "Sobre la incidencia de la imagen en la atenuación pragmática». En Mihatsch, W. y M. Albelda (eds.); Revista Internacional de Lingüistica (RILI) 27, 19-32.

Albelda, M., Briz, A., Cestero, M., KotwicA, D. y Villalba, C. (2014). «Ficha metodológica para el análisis pragmático de la atenuación en corpus discursivos del español. (ES.POR.ATENUACIÓN)», Oralia 17, pp. 7-62.

BARTOL, E. (2013). «La atenuación y la intensificación: herramientas para un mensaje adecuado», Tinkuy: Boletín de investigación y debate 13, pp. 47-55.

BRAVO, D. (1998). «Face y rol social: eficiencia comunicativa en encuentros entre hablantes nativos y no nativos del español», Revista de Estudios de Adquisición de la Lengua Española 8, pp. 11-41.

Bravo, D. (1999). «¿Imagen ‘positiva’ vs. imagen ‘negativa’? Pragmática socio-cultural y componentes de face», Oralia 2, pp. 155-184.

BRAVO, D. (2010). «Pragmática sociocultural. La configuración de la imagen social como premisa socio-cultural para la interpretación de actividades verbales y no verbales de la imagen». En Orletti, F. L. y Mariottini (eds.); (Des)cortesía en español. Espacios teóricos y metodológicos para su estudio. Estocolmo-Roma: Università degli Studi Roma TreEDICE, pp. 19-46.

HERNÁNDEZ FLORES, N. (2003). «Cortesía y contextos socioculturales en la conversación española de familiares y amigos». En Bravo, D. (ed.); Actas del Primer Coloquio del Programa EDICE. La perspectiva no etnocentrista de la cortesía: identidad sociocultural de las comunidades hispanohablantes. Estocolmo: Universidad de Estocolmo, pp. 121127.

HERnÁndez Flores, N. (2013). «Actividad de imagen. Caracterización y tipología en la interacción comunicativa», Pragmática Sociocultural/Sociocultural Pragmatics 1 (2), pp. 1-24.

GofFMAN, E. ([1959] 2009). La presentación de la persona en la vida cotidiana. Buenos Aires: Amorrortu.

JACOBSON, H.E. (2001). «La comunicación con pacientes hispano-hablantes en Estados Unidos»,Panace@ 2 (3), pp.58-66.

Rodríguez Salvador, J.J. (2010). Comunicación Clínica: Cómo dar Malas Noticias. Recuperado el 01/05/2017, de http:/www.doctutor.es/wp-content/uploads/2010/03/DarMalas-Noticias-JJ-Rodriguez-S-2010.pdf 